\title{
VIABILIDADE ECONÔMICA DO POLICULTIVO DE GIRINOS DE RÃ-TOURO COM ALEVINOS DE TILÁPIA DO NILO DURANTE INVERNO E BAIXA DENSIDADE
}

Economic viability of polyculture of bull frog tadpoles with Nile tilapia fingerlings during winter and low density

Viabilidad económica del policultivo de renacuajo de rana toro com alevines de tilapia del Nilo durante invierno y baja densidad

\author{
Nathália de Souza Ferreira ${ }^{1}$, Patrícia de Souza Ferreira ${ }^{1}$, Marcelo Maia Pereira ${ }^{2}$ \\ ${ }^{I}$ Centro Universitário de Valença, UNIFAA, Valença, RJ, Brasil. \\ ${ }^{2}$ Fundação Instituto de Pesca do Estado do Rio de Janeiro, Rio das Flores, RJ, Brasil. \\ * Fundação Instituto de Pesca do Estado do Rio de Janeiro, Rio das Flores, RJ, Brasil. CEP:.27660-000. e-mail \\ mmaiap2001@yahoo.com.br.
}

Artigo recebido em 29/07/2020 aprovado em 03/11/2020 publicado em 17/03/2021.

\section{RESUMO}

O policultivo é uma prática excelente para pequenos produtores para diversificar a produção. Este projeto foi realizado com objetivo avaliar a criação em policultivo de girinos de rã-touro com alevinos de tilápia do Nilo durante inverno e em baixa densidade e a sua viabilidade econômica. Houve no estudo um total de 70 animais por unidade amostral em três caixas de alvenaria, com volume útil foi de $700 \mathrm{~L}$ e densidade de 1 animal para cada $10 \mathrm{~L}$, sendo 6 girinos para cada alevino, durante 46 dias experimentais, para avaliar o crescimento dos animais foram realizadas quatro biometrias. Os parâmetros avaliados foram: peso vivo dos animais por espécie (g), sobrevivência (\%), ganho de peso $(\mathrm{g})$ e conversão alimentar aparente $(\mathrm{g} / \mathrm{g})$, os dados de custos foram obtidos para viabilidade econômica foram lucro bruto $(\mathrm{R} \$)$, lucro líquido $(\mathrm{R} \$)$ e o tempo de retorno do investimento para três situações (local de criação existente, compra de caixa de água plástica e construção em alvenaria), a estatística foi descritiva. Os parâmetros zootécnicos avaliados se mostraram dentro dos parâmetros aceitáveis para cada espécie. O sistema de policultivo nas condições proposta foi viável para criação das duas espécies aquáticas e também para os pequenos produtores que possuem infraestrutura existente na propriedade e mão de obra familiar.

Palavras-chave: Administração, piscicultura, ranicultura.

\begin{abstract}
Polyculture is an excellent practice for small producers to diversify production. This project was carried out with the objective of evaluating the breeding of bullfrog tadpoles with Nile tilapia fry during the winter and the low density and its economic viability. In total, 70 animals were studied per sampling unit in three masonry boxes, with a useful volume of $700 \mathrm{~L}$ and density of 1 animal for each $10 \mathrm{~L}$, with 6 tadpoles for each fry, during 46 experimental days, for the evaluation or growth of the animals four biometrics were performed. The measurement parameters were: live weight of animals by species $(\mathrm{g})$, survival $(\%)$, weight gain $(g)$ and apparent food recovery $(g / g)$, cost data were used for economic viability with gross profit $(R \$)$, net profit $(R \$)$ and the return on investment for three situations (place of existing creation, purchase of plastic water box and construction in masonry), a statistic was descriptive. The zootechnical parameters apply within the acceptable limits for each species. The polyculture system under the proposed conditions was feasible for the creation of two aquatic species and also for small products that have the existing infrastructure on the property and family labor.
\end{abstract}

Keywords: Administration, fish farming, frog farming. 


\section{RESUMEN}

El policultivo es una práctica excelente para que los pequeños agricultores diversifiquen la producción. Este proyecto se llevó a cabo para evaluar la creación en policultivo de renacuajo de rana toro con alevines de tilapia del nilo durante el invierno y en baja densidad y su viabilidad económica. En el estudio hubo un total de 70 animales por unidad de muestra en tres cajas de mampostería, con un volumen útil de 700 L y una densidad de 1 animal por cada 10 L, teniendo 6 renacuajos por cada alevín, durante 46 días experimentales, para evaluar el crecimiento de los animales se realizaron cuatro datos biométricos. Los parámetros evaluados fueron: peso vivo de los animales por especie ( $\mathrm{g}$ ), supervivencia (\%), aumento de peso $(\mathrm{g})$ y conversión aparente de alimento $(\mathrm{g} / \mathrm{g})$, los datos de costos obtenidos para la viabilidad económica fueron ganancias brutas $(R \$)$, ganancia neta $(R \$)$ y retorno de la inversión en tres situaciones (lugar de creación existente, compra de caja plástica de agua y construcción de mampostería), las estadísticas fueron descriptivas. Se encontró que los parámetros zootécnicos evaluados estaban dentro de parámetros aceptables para cada espécie. El sistema de policultivo en las condiciones propuestas fue factible para la creación de las duas especies acuáticas y también para pequeños productores que tienen infraestructura existente en la propiedad y mano de obra familiar.

Descriptores: Administración, piscicultura, ranicultura.

\section{INTRODUÇÃO}

O policultivo é utilizado principalmente para aumentar a produção utilizando os recursos disponíveis de forma mais eficiente, é um sistema de produção integrado no qual duas ou mais espécies aquáticas são cultivadas no mesmo local (SILVA et al., 2006). Utilizando-se de organismos com diferentes hábitos e distribuídos em distintos espaços na coluna d'água (ZIMMERMANN, 2000).

$\mathrm{Na}$ aquicultura mundial visando a eficiente ocupação do espaço físico, o policultivo proporciona aumento da produtividade e rentabilidade dos empreendimentos aquícolas (CASALI et al., 2005). Esse sistema é altamente produtivo e pode ser muito lucrativo, mas levar esses peixes para o mercado obtendo lucro pressupõe-se um grande esforço científico e tecnológico (CERDÁ-REVERTER, 2019).

A tilápia do Nilo (Oreochromis niloticus) exibe características apropriadas e ampla disponibilidade de alevinos para uso em sistemas de policultivo. Esta espécie é bastante rústica, com alimentação diversificada, alimenta-se bem de ração e tem uma carne de excelente qualidade que é amplamente cultivada no Brasil (HAYASHI et al., 1999).
As rãs são animais pecilotérmicos assim como outros organismos aquáticos como peixes, camarões e moluscos, ou seja, o metabolismo varia de acordo com a temperatura do meio em que vive o que pode prejudicar na adequada alimentação dos animais. Com as variações da temperatura o consumo do alimento altera-se e com isso leva a momentos em pode haver sobra de alimento ou a oferta pode ser insuficiente (LIMA et al., 2003).

A tilápia por ser onívora não irá predar os anfíbios, podendo assim ter êxito na criação conjunta com rãs, se alimentando das sobras de ração. Com a renovação continua de água, que irá remover constantemente as sobras de ração e os dejetos produzidos pelos animais, não há necessidade de limpeza diária das instalações, reduzindo os custos com mão de obra e melhorando a qualidade da água (CASTRO, 2013).

A alta densidade de animais associado ao pequeno volume de água nas baias, grande quantidade de fezes e restos de ração facilita a proliferação de bactérias patogênicas que iram causar baixo desempenho e piorar as condições higiênicas (CASALI et al., 2005). 
A densidade de estocagem é um fator determinante no custo de produção em relação ao que foi investido, pois a elevada densidade pode ser considerada um potencial estressor, que pode levar a alterações fisiológicas com consequente redução do crescimento (GOMES et al., 2000). No entanto a falta de indicadores econômicos gera grande incerteza e representa um entrave para o desenvolvimento dessa atividade (SANTOS, 2008).

Analisando a viabilidade econômica do projeto será possível fazer projeções de todo o gasto envolvido com o investimento inicial, operação e manutenção e determinar as estimativas de lucros do projeto (VILELA et al., 2013).

Fatores múltiplos podem afetar a viabilidade econômica de um policultivo como o preço de comercialização no mercado, custo da ração, conversão alimentar, taxa de sobrevivência e preço das formas jovens (CARNEIRO et al., 1999).

É inegável a necessidade de se fazer um bom planejamento e gerenciamento das despesas e receitas decorrentes das pisciculturas utilizando-se de ferramentas que permitam avaliar os custos que podem auxiliar piscicultores ou responsáveis técnicos a avaliar e selecionar alternativas adequadas que garantam a viabilidade econômica do empreendimento (VILELA et al., 2013).

O objetivo deste artigo é avaliar a implantação de um policultivo de girinos de rã-touro com alevinos de tilápia do Nilo durante inverno e baixa densidade visando mostrar aos produtores a viabilidade econômica e financeira, ou não, da atividade proposta em termos de custos e resultados.

\section{MATERIAIS E MÉTODOS}

Local de estudo

O estudo foi conduzido no Centro de Treinamento em Aquicultura Sul-Fluminense localizado em Rio das Flores, no ranário experimental,
Lat -22.15 Long -43.57. O período experimental foi nos meses de agosto e setembro (inverno no Hemisfério Sul).

Os procedimentos adotados foram aprovados pela Comissão de Ética no Uso de Animais (CEUA) da instituição, protocolo de número 001/18, e estão de acordo com os princípios éticos na experimentação animal elaborado pelo Colégio Brasileiro de Experimentação Animal (COBEA).

\section{Condições de criação}

Os girinos de rã-touro (Lithobates catesbeianus) e alevinos de tilápia do Nilo (Oreochromis niloticus) foram distribuídos em três caixas de alvenaria de $0,90 \mathrm{~m}$ de largura e $2,70 \mathrm{~m}$ de comprimento e $1 \mathrm{~m}$ de altura, porém o volume útil foi de 700 L (1 animal por litro), com entrada de água pela superfície, a sua saída oposta e na base da instalação para eliminação de água de qualidade inferior. Houve 154 renovação constante diária de água de $200 \%$ ao longo de 24 horas.

Em cada repetição foram distribuídos 60 girinos de rã-touro e 10 alevinos de tilápia do Nilo revertidos, no total de 70 animais por unidade amostral, com isso a densidade inicial foi de 1 animal por $10 \mathrm{~L}$ (densidade populacional baixa). O peso inicial dos girinos de rã-touro foi de $6,1 \mathrm{~g}$ e dos alevinos de tilápia do Nilo de $1,9 \mathrm{~g}$.

A alimentação dos girinos de rã-touro e dos alevinos de tilápia do Nilo foi através de ração comercial para peixes onívoros com 320 g/Kg de proteína bruta que foi moída por peneira de $0,5 \mathrm{~mm}$ para ser oferecida duas vezes ao dia (SEIXAS FILHO et al., 1998) na quantidade de 14 gramas diárias em todos os dias de experimento para cada repetição duas vezes ao dia as $9 \mathrm{e}$ as 15 horas.

A temperatura da água e do ambiente foram medidos diariamente ás 8 e as 16 horas todos os dias com termômetro digital com sensor eletrônico e o pH 
da água todos os dias as 8 horas com medidor de $\mathrm{pH}$ digital.

As biometrias foram uma inicial e com 15, 29 e 46 dias (final), onde os animais foram contados e divididos por espécie e depois pesados todos juntos em balança digital com precisão de $0,001 \mathrm{~g}$.

Estatística descritiva, Cálculos de custos e Viabilidade Econômica

Parâmetros avaliados para criação dos animais e obtenção de índices zootécnicos foram: peso vivo dos animais por espécie (g), sobrevivência (\%), ganho de peso $(\mathrm{g})$ e conversão alimentar aparente $(\mathrm{g} / \mathrm{g})$. Dados coletados foram inseridos em planilha no software Microsoft Excel® para uma análise descritiva. Curvas de crescimento em peso vivo (g) ao longo do tempo experimental (dias) polinomial de segundo grau foram elaboradas com auxílio do software Microsoft Excel® para as duas espécies.

Informações de custos dos insumos foram obtidas para uma análise de custos fixo e variáveis e para análise da viabilidade econômica da criação em policultivo de girinos de rã-touro coma alevinos de tilápia do Nilo. Os dados de viabilidade foram lucro bruto $(\mathrm{R} \$)$, lucro líquido $(\mathrm{R} \$)$ e o tempo de retorno do investimento (ciclo de produção) para três situações (local para criação pré-existente, compra de caixa de água plástica e construção em alvenaria).

\section{RESULTADOS E DISCUSSÃO}

A temperatura da água às 8 horas foi em média de $19,2 \pm 2,1^{\circ} \mathrm{C}$ e às 16 horas de $21,1 \pm 2,9^{\circ} \mathrm{C}$, a temperatura do ambiente ás 8 horas foi em média de $21,0 \pm 3,1^{\circ} \mathrm{C}$ e ás 16 horas de $24,1 \pm 2,2^{\circ} \mathrm{C}$. O pH da água do policultivo foi de $7,1 \pm 0,1$.

$\mathrm{O}$ crescimento dos girinos de rã-touro ocorreu de forma satisfatória, desacelerando no ganho de peso diário ao final do experimento e o peso final foi de qualidade para inicio do clímax de metamorfose
(Figura 1). Os alevinos de tilápia do Nilo já apresentaram curva crescente de ganho de peso diário, o que foi normal para esta fase da vida deste peixe (Figura 1).

A sobrevivência média dos girinos de rã-touro foi de $96 \%$ e dos alevinos de tilápia do Nilo foi de 100\%. A mortalidade dos girinos foi baixa e dos alevinos não houve e esse foi um excelente resultado para policultivo (Tabela 1). O ganho de peso médio para girinos de rã-touro foi $6,8 \mathrm{~g}$ e os alevinos de foi de 5,3 g (Tabela 1). A conversão alimentar aparente média do sistema de policultivo foi de $1,5 \mathrm{~g} / \mathrm{g}$.

Figura 1. Curvas de crescimento para girinos de rã-touro e de alevinos de tilápia do Nilo criados em sistema de policultivo.

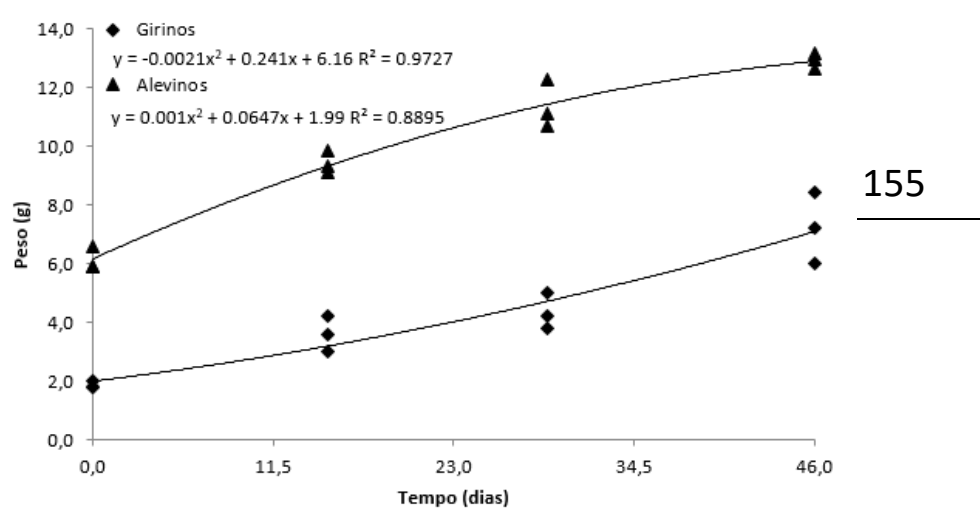

Tabela 1. Índices zootécnicos (sobrevivência; ganho de peso e conversão alimentar aparente (CAA)) do policultivo entre girinos de rã-touro e de alevinos de tilápia do Nilo durante inverno e em baixa densidade.

\begin{tabular}{cccccc}
\hline & \multicolumn{2}{c}{ Sobrevivência (\%) } & \multicolumn{2}{c}{ Ganho de Peso $(\mathrm{g})$} & \multirow{2}{*}{ CAA (g/g) } \\
\cline { 1 - 5 } Repetição & Alevinos & Girinos & Alevinos & Girinos & \\
\cline { 1 - 5 } 1 & 100 & 98,3 & 4,2 & 6,0 & 1,66 \\
2 & 100 & 96,7 & 5,4 & 7,0 & 1,44 \\
3 & 100 & 95,0 & 6,4 & 7,3 & 1,41 \\
\hline Média & 100 & 96,0 & 5,3 & 6,8 & 1,50 \\
\hline
\end{tabular}

O custo variável deste sistema de policultivo para pequeno produtor foi o insumo ração comercial e os animais. A ração comercial para peixes onívoros com $32 \%$ de proteína bruta para peixes onívoros varia no comércio do Estado do Rio de Janeiro de 50 a 60 reais, os girinos de rã-touro com mais de 30 dias variam de 0,06 a 0,12 reais e os alevinos de tilápia do Nilo de 0,12 a 0,15 reais, para efeitos de cálculo o valor 
maior foi o considerado (Tabela 2), a mão-obra não foi considerada.

O local de criação pode ser instalação préexistente na propriedade ou iniciar a construção em alvenaria ou aquisição de uma caixa plástica de água, com isso foi sugerido três situações de custos (Tabela 2).

Tabela 2. Custo de produção no policultivo de girinos de rã-touro com alevinos de tilápia do Nilo para três situações por unidade de criação.

\begin{tabular}{cccc}
\hline Item & Valor unitário R\$ & Quantidade & Total RS \\
\hline \multicolumn{4}{c}{ Local de criação pré-existente } \\
\hline Ração (Kg) & 2,40 & 0,664 & 1,55 \\
Girinos de rã-touro (un) & 0,12 & 60 & 7,20 \\
Alevinos de tilápia do Nilo (un) & 0,15 & 10 & 1,50 \\
Custo Total (RS) & - & - & $\mathbf{1 0 , 2 5}$ \\
Custo Unitário (R\$) & - & - & $\mathbf{0 , 1 5}$ \\
\hline \multicolumn{4}{c}{ Caixa de criação alvenaria } \\
\hline Ração (Kg) & 2,40 & 0,664 & 1,55 \\
Girinos de rã-touro (un) & 0,12 & 60 & 7,20 \\
Alevinos de tilápia do Nilo (un) & 0,15 & 10 & 1,50 \\
Alvenaria com mão de obra & 500,00 & 500,00 & 500,00 \\
Custo Total (RS) & - & - & $\mathbf{5 1 0 , 2 5}$ \\
Custo Unitário (R\$) & - & - & 7,29 \\
\hline \multicolumn{2}{c}{ Caixa de água para criação } \\
\hline Ração (Kg) & 2,40 & 0,664 & 1,55 \\
\hline Girinos de rã-touro (un) & 0,12 & 60 & 7,20 \\
Alevinos de tilápia do Nilo (un) & 0,15 & 10 & 1,50 \\
Caixa de água (1000 L); tubulação & 300,00 & 300,00 & 300,00 \\
Custo Total (RS) & - & - & $\mathbf{3 1 0 , 2 5}$ \\
Custo Unitário (R\$) & - & - & $\mathbf{4 , 4 3}$ \\
\hline
\end{tabular}

Após esse período de experimentação, esses animais teriam preço de comercialização de 0,18 a 0,20 reais os girinos de rã-touro e os alevinos de tilápia do Nilo de 0,20 a 0,22 reais de acordo com preços praticados no estado do Rio de Janeiro. Para cálculos de lucro bruto foram utilizados os dados de sobrevivência das espécies (100\% para alevinos de tilápia do Nilo e $96 \%$ para girinos de rã-touro) e o menor valor de venda inicialmente relatado.

A partir disso, o lucro bruto para uma criação de policultivo com local de criação já existente na propriedade seria de 12,26 reais e lucro líquido de 2,01 reais em 46 dias e de 15,90 reais em um ano.

Para uma criação em policultivo com necessidade de compra de uma caixa de água ou construção em alvenaria, a atividade precisaria de 149 ciclos de criação para custear a caixa de água e de 248 ciclos para custear uma obra de alvenaria, com um tempo de retorno considerado muito alto.
O presente experimento foi realizado entre os meses de agosto e setembro, a temperatura média da água foi de $19,2 \pm 2,1^{\circ} \mathrm{C}$ às 8 horas e de $21,1 \pm 2,9^{\circ} \mathrm{C}$ às 16 horas. A tilápia é uma espécie tropical cuja temperatura ideal para seu desenvolvimento varia entre 26 a $28^{\circ} \mathrm{C}$ (HEIN e BRIANESE, 2004), a faixa ideal para um desenvolvimento ótimo da rã-touro é entre 25 a $28^{\circ} \mathrm{C}$ (MAZZONI, 2001). Portanto ambas as espécies ficaram abaixo da temperatura ideal da água durante todo do experimento e mesmo assim apresentaram crescimento.

As tilápias não resistem a temperaturas por volta de 8 a $14^{\circ} \mathrm{C}$ que geralmente são letais (OSTRENSKY e BOOGER,1998), neste estudo foi observado que os alevinos de tilápia em temperaturas mínimas de $17,1^{\circ} \mathrm{C}$, tiveram uma taxa de sobrevivência de $100 \%$. Girinos de rã touro tem sua metamorfose ligada diretamente a temperatura da água, quando a temperatura oscila entre 15 e $18^{\circ} \mathrm{C}$, o 156 período de metamorfose que necessitaria de 2 a 4 meses pode aumentar de 6 a 10 meses (VIZOTTO, 1981).

As tilápias não podem sobreviver a temperaturas inferiores a 10 e $12^{\circ} \mathrm{C}$ por mais que alguns dias (ERNST et al., 1991), mas como observado em outro estudo a tilápia do Nilo Oreochromis niloticus tem a capacidade de sobreviver a temperaturas baixas se antes do início do inverno for feito uma adaptação dos peixes em água que tenha uma salinidade ambiental próxima à isotonicidade, melhorando sua tolerância ao frio (HASSAN et al., 2013). Em nossa pesquisa não foi realizado testes para avaliar a salinidade da água, mas esse pode ser um dos motivos pelo qual $100 \%$ das tilápias puderam sobreviver até o fim do experimento.

Apesar dos índices avaliados como ganho em peso diário e consumo de ração, terem desempenho inferior aos dados que foram obtidos durante altas temperaturas do ambiente como ocorrem no verão 
(CARNEIRO et al., 1999; SAMPAIO e BRAGA 2005), um índice positivo no inverno foi o percentual de sobrevivência, o que pode ser explicado já que em temperaturas elevadas o consumo de oxigênio é praticamente duplicado a cada $10^{\circ} \mathrm{C}$ de aumento na temperatura da água, e a concentração de oxigênio é sensível à temperatura, quanto mais quente menor a concentração de $\mathrm{O} 2$ na água, além da temperatura diminuir a velocidade das atividades fisiológicas para peixes (KUBITZA, 1998).

A alimentação dos animais com ração comercial com $320 \mathrm{~g} / \mathrm{Kg}$ de teor de proteína bruta possivelmente atendeu aos $277,00 \mathrm{~g} / \mathrm{Kg}$ de proteína digestível exigência para um bom desenvolvimento dos girinos de rã-touro (PINTO et al. 2015) e também atendeu as exigências para alevinos de tilápia do Nilo (Oreochromis niloticus) de $320,00 \mathrm{~g} / \mathrm{Kg}$ de proteína bruta (Furuya et al., 2000), isso também explica porque mesmo em condições adversas houve crescimento satisfatório.

Os parâmetros para a conversão alimentar aparente (CAA) do policultivo dos girinos com os alevinos foi de 1,41 a 1,66, que está dentro dos parâmetros aceitáveis e semelhantes aos encontrados para girinos de rã-touro (LIMA et al., 2003) e também para tilápias onde foram encontrados 1,53 (SAMPAIO e BRAGA, 2005) e de 1,54 a 1,75 (MARENGONI, 2006).

Neste trabalho a alimentação foi oferecida duas vezes ao dia as 9 e as 15 horas, horários em que a temperatura da água estaria mais elevada no inverno, para que assim tanto os girinos quanto alevinos teriam um consumo maior de ração se comparados com horários em que a temperatura estaria mais fria.

Pois temperaturas registradas durante $\mathrm{o}$ período do inverno podem interferir no consumo da ração, com isso se recomenda que a alimentação seja oferecida no horário em que as condições de temperatura da água estão mais elevadas, o que melhorara o consumo do alimento, mesmo que a ração seja ofertada nos horários com temperaturas mais elevadas ainda assim foi inferior ao consumo se comparado ao verão para alevinos de tilápia do Nilo (GRAEFF e PRUNER, 2006).

Entretanto para girinos de rã-touro, a temperatura da água mais baixa como a do trabalho em questão em relação à temperatura ideal de criação de $25^{\circ} \mathrm{C}$ (HOFFMAN et al., 1989), faz o nível do hormônio do crescimento aumentar nesses animais e consequentemente os girinos aumentarem o tamanho corporal, entretanto com baixos níveis dos hormônios da tireoide faz que haja estabilização do processo da metamorfose (ÁLVAREZ e NICIEZA, 2002).

Menores densidades, obtêm-se girinos maiores e lotes mais uniformes com melhor taxa de sobrevivência (HAYASHI et al., 2004), com o aumento da densidade de estocagem de tilápias, o ganho de peso e o ganho de peso diário diminuem 157 (MAEDA et al., 2010), a partir das afirmativas acima se justifica o uso da baixa densidade durante período estudado para que parâmetros como ganho de peso e índice de sobrevivência pudessem ter os melhores resultados possíveis dadas as condições térmicas do inverno. Nesta pesquisa foi verificado $\mathrm{pH}$ da água entre 7,0 a 7,2 a faixa de $\mathrm{pH}$ compreendida entre 6,0 a 7,0 é considerada ideal para girinos de Rana catesbeiana (ALVES, 1995), o pH ideal da água para tilápias deve ser mantido entre 6 a 8,5 (KUBITZA e KUBITZA, 2000), apesar do pH ligeiramente acima do ideal para girinos, esse parâmetro não afetou a criação e o policultivo.

A partir dos dados observados na pesquisa como custo de produção (Tabela 2) em três situações possíveis como: local de criação pré-existente, caixa de criação de alvenaria e caixa de água para criação (1000L). Podemos perceber que o policultivo de girinos de rã-touro com alevinos de tilápia do Nilo durante inverno é viável economicamente desde que o 
produtor já tenha local para criação em sistema de policultivo para que tenha um retorno financeiro, pois nas outras duas opções seriam necessários 248 ciclos de criação para custear uma obra de alvenaria e 149 ciclos para custear a caixa de água.

O melhor cenário seria em um local de criação pré-existente para complementar a renda da propriedade, ou em um sistema de produção que será integrado como o cultivo de hortaliças em hidroponia ou mesmo aproveitando a infraestrutura implantada nos projetos de irrigação das hortaliças (HUNDLEY et al., 2013).

Aquaponia trata-se de um sistema de criação de peixes associada ao cultivo de hortaliças, onde a água rica em matéria orgânica gerado pelos dejetos que sai do tanque dos peixes seja bombeada para o canal hidropônico onde os nutrientes contidos na água para seu crescimento, e como contrapartida efetua a limpeza da água que retornará por gravidade em boas condições aos peixes (BRŠĆAN, 2015), com isso o policultivo dos organismos aquáticos seria mais uma forma de diversificação da produção.

Pequenos produtores rurais precisam diversificar as produções e utilizar área produtiva da melhor forma possível, com isso o policultivo nas condições deste trabalho seria uma opção para aqueles que já possuem um possível local de criação o que traria um melhor retorno financeiro que seria de 12,26 reais e lucro líquido de 2,01 reais em 46 dias e de 15,90 reais em um ano em uma pequena área.

\section{CONCLUSÃO}

O policultivo de girinos de rã-touro com alevinos de tilápia do Nilo durante inverno se mostrou viável economicamente, apresentou parâmetros como a conversão alimentar aparente (CAA), taxa de sobrevivência, ganho de peso diário dentro dos parâmetros aceitáveis e a opção viável para o policultivo seria um local com infraestrutura existente na propriedade e com isso mais uma renda extra para pequenos produtores.

\section{AGRADECIMENTO}

A Fundação Carlos Chaga Filho de Amparo à Pesquisa do Estado do Rio de Janeiro (FAPERJ) pela concessão da bolsa de iniciação científica, processo E26/202.092/2019.

Todos os autores declararam não haver qualquer potencial conflito de interesses referente a este artigo.

\section{REFERÊNCIAS}

ÁLVAREZ, D.; NICIEZA, A.G. Effects of induced variation in anuran larval development on postmetamorphic energy reserves and locomotion. Oecologia (2002) 131:186-195. Doi. 10.1007/s00442002-0876-x.

ALVES, A.R. Estudo comparativo da criação de girinos de rã-touro (Rana catesbeiana Shaw, 1802) em dois tipos de tanque. 53 p. Mestrado (Dissertação de Mestrado em Zootecnia) - Universidade Federal de Viçosa, 1995.

BRŠĆAN, Ivan Marinović. Integrar criação de peixes com hortaliças economiza $90 \%$ de água e elimina químicos. Embrapa, 28 abr. 2015. Disponível em: https://www.embrapa.br/busca-de-noticias//noticia/2767622/integrar-criacao-de-peixes-comhortalicas-economiza-90-de-agua-e-eliminaquimicos. Acesso em: 20 jul. 2020.

CARNEIRO, Paulo César Falanghe; MARTINS, Maria Inez Espagnolli Geraldo; CYRINO, José Eurico Possebon. Estudo de caso da criação comercial da tilápia vermelha em tanques-rede: avaliação econômica. Informações Econômicas, SP, v. 29, n. 8, p. 52-61, ago/set. 1999.

CASALI, Alex Poeta; MOURA, Onofre Maurício; MENDES, Richélita do Rosário Brito; CAMPOS, Valnir de Meneses. Efeito da Densidade de Estocagem no Desempenho de Rã-Touro (Rana catesbeiana) em Recria. R. Bras. Zootec., v. 34, ed. 6, p. 1828-1834, 2005.

CASTRO, C. S. Frequência alimentar e período de alimentação no cultivo de rã-touro em tanque-rede. 2013. Tese (Pós-Graduação em Zootecnia) Universidade Estadual Paulista Faculdade de Medicina Veterinária e Zootecnia Câmpus de Botucatu, 2013. 
CERDÁ-REVERTER, José Migue. PEIXES CARNÍVOROS, VEGETARIANOS E AQUICULTURA INSUSTENTÁVEL. Panorama da aquicultura, Rio de Janeiro, v. 29, ed. 171, p. 4450, janeiro 2019.

ERNST, Douglas H.; WATANABE, Wade O.; ELLINGSON, Lisa J.; WICKLUND, Robert I.; OLLA, Bori L. Commercial-Scale Production of Florida Red Tilapia Seed in Low- and BrackishSalinity Tanks. World Aquaculture Society, v. 22, p. 36-44, mar. 1991.

FAO. Status and trends: overview. In: FAO. The State of World Fisheries and Aquaculture: opportunities and challenges. Rome, 2014. p. 3-9.

FURUYA, Wilson Massamitu; HAYASHI, Carmino; FURUYA, Valéria R. Barriviera; SOARES, Claudemir Martins.Exigência de Proteína para Alevino Revertido de Tilápia do Nilo (Oreochromis niloticus). Rev. bras. zootec., v. 29, ed. 6, p. 19121917, 4 ago. 2000

GOMES, Paulo Cezar; RAMALHO, Roberta Marangon; ROSTAGNO, Horacio Santiago; ALBINO, Luiz Fernando Teixeira; NASCIMENTO, Adriana Helena. Efeito do complexo multienzimatico nos valores de energia metabolizavel e coeficientes de digestibilidade dos aminoácidos do triticale para aves. Revista Brasileira de Zootecnia, v.29, n.6, p.22682275, 2000.

GRAEFF, Álvaro; PRUNER, Evaldo Nazareno. Variáveis que podem interferir na sobrevivência e desenvolvimento da Tilapia nilotica (Oreochromis niloticus) na região fria do Estado de Santa Catarina. Comunicación Científica, p. 70-79, 2006.

HASSAN, B.; El-Salhia M. ; KHALIFA A.; ASSEM H. ; AL BASOMY A.; El-Sayed M. Environmental isotonicity improves cold toleranceof Nile tilapia,Oreochromis niloticus, in Egypt. Egyptian Journal of Aquatic Research, National Institute of Oceanography and Fisheries, v. 39, p. 59-65, 24 maio 2013.

HAYASHI, Carmino; BOSCOLO, Wilson Rogério; SOARES, Claudemir Martins; BOSCOLO, Vilson Roberto; GALDIOLI, Eliana Maria. Uso de diferentes graus de moagem dos ingredientes em dietas para a tilápia-do-Nilo (Oreochromis niloticus L.) na fase de crescimento. Acta Scentiarium, v.21, n.3, p.733-737, 1999.

HAYASHI, Carmino; SOARES Claudemir Martins; GALDIOLI Eliana Maria; FURUYA Valéria Rossetto Barriviera; BOSCOLO Wilson Rogério. Desenvolvimento de Girinos de Rã-Touro (Rana catesbeiana, Shaw, 1802) Cultivados em Diferentes Densidades de Estocagem em Tanques-rede. R. Bras. Zootec., v. 33, n. 1, p. 14-20, 2004.
HEIN, Gelson; BRIANESE, Raul Henrique. Modelo emater de produção de tilápia. Emater, 2004.

HOFFMANN, D.F.; LEBOUTE, E. M.; SOUZA, S.M.G. Efeito da temperatura e desenvolvimento de girinos de rã-touro (Rana catesbeiana Shaw, 1802). Revista Sociedade Brasileira Zootecnia, v.18, n.6, p.557-566, 1989.

HUNDLEY, G.M.C.; NAVARRO, R.D.; FIGUEIREDO, C.M.G.; NAVARRO, F.K.S.P.; PEREIRA, M.M.; RIBEIRO FILHO, O.P.; SEIXAS FILHO, J.T. Aproveitamento do efluente da produção de tilápia do Nilo para o crescimento de manjericão (Origanum basilicum) e manjerona (Origanum majorana) em sistemas de aquaponia. Revista Brasileira de Agropecuária Sustentável, 3:51-55, 2013.

KUBITZA, Fernando. A relação entre pH, gás carbônico, alcalinidade e dureza e sua influência no desempenho e saúde dos peixes e camarões. Panorama da aqüicultura, n. 163, 30 set. 2017.

KUBITZA, Fernando. Qualidade da Água na Produção de Peixes: Parte III (Final). Panorama da aquiicultura, v. 8, n. 47, p. 35-43, maio 1998.

KUBITZA, Fernando; KUBITZA, Ludmilla M. M. Tilapias: Qualidade da água, sistemas de cultivo, planejamento da produção, manejo nutricional e alimentar e sanidade. Parte I. Panorama da aquicultura, n. 59, jun. 2000.

LIMA, Samuel Lopes; CASALI, Alex Poeta; AGOSTINHO, Cláudio Angelo. Desempenho zootécnico e percentual de consumo de alimento de rãtouro (Rana catesbeiana) na fase de recria (pósmetamorfose) do sistema anfigranja. R. Bras. Zootec., Viçosa, v. 32, n. 3, p. 505-511, maio 2003.

MAEDA, Henrique; SILVA Paulo Cesar; OLIVEIRA Raquel Priscilla de Castro; AGUIAR Marília da Silva; PÁDUA Delma Machado Cantisani; MACHADO Nádia Pales; RODRIGUES Valéria; SILVA Rene Henrique. Densidade de estocagem na Alevinagem de tilápia-do-nilo em tanque-rede. Ci. Anim. Bras., Goiânia, v. 11, n. 3, p. 471-476, set. 2010.

MARENGONI, N.G. produção de tilápia do nilo Oreochromis niloticus (linhagem chitralada), cultivada em tanques-rede, sob diferentes densidades de estocagem. Archivos de Zootecnia, v. 55, n. 210, p. 127-138, jun. 2006.

MAZZONI, R. (Ed.) Ranicultura: manual básico para inversores. Montevidéo: Proyecto Ranicultura Dinara -IIP, 2001, 20 p.

OSTRENSKY, Antonio; BOOGER, Walter. Piscicultura: Fundamentos e técnicas de manejo. Cuíaba - RS: Agropecuária LTDA., 1998. 221 p. 
PINTO, D.F.H.; MANSANO, C.F.M.; STÉFANI, M.V.; PEREIRA, M.P. Optimal digestible protein level for bullfrog tadpoles. Aquaculture, 440, 12-16, 2015.

http://dx.doi.org/10.1016/j.aquaculture.2015.01.025

SAMPAIO, J.M.C; BRAGA, L.G.T. Cultivo de tilápia em tanques-rede na barragem do Ribeirão de Saloméa: - Floresta Azul - Bahia. Rev. Bras. Saúde Prod. An., v. 6, n. 2, p. 42-52, 2005.

SANTOS, Janaína Gomes Araújo. Frequências e formas de fornecimento de ração para tilápia do nilo criada em sistema raceway. 2008. $58 \mathrm{f}$. Tese (Doutorado) - Curso de Pós-graduação em Ciência Animal, Universidade Federal de Goiás Escola de Veterinária, Goiânia, 2008.

SEIXAS FILHO, J.T., MELLO, S.C.R.P., VEIGA, R.C.A., MIRANDA, R.G.B., SANTOS, C.A.N., 1998. Efeito da granulometria da ração sobre o desempenho de girinos de Rana catesbeiana. Revista Brasileira de Zootecnia 27, 224-230.

SILVA, Leonardo Bolognesi; BARCELLOS, Leonardo José Gil; QUEVEDO, Rosmari Mezzalira;
SOUZA, Silvia Maria Guimaraes. Alternative species for traditional carp polyculture in southern South America: Initial growing period. Science direct, $\mathrm{p}$. 417-428, 2006.

VILELA, Maria Celma; ARAÚJO, Kleber Domingues; MACHADO, Lúcio de Souza; MACHADO, Michele Rilany Rodrigues. Análise da viabilidade econômico-financeira de projeto de piscicultura em tanques escavados. Custos e @gronegócio, Pernambuco, v. 9, n. 3, p. 154-173, jun. 2013.

VIZOTTO, L.D. Produção de girinos. In: SIMPÓSIO BRASILEIRO SOBRE AQUICULTURA. ENCONTRO NACIONAL DE RANICULTORES, 1980, Jaboticabal, SP. Anais [...]. Brasília, DF, 1981. 125-151 p.

ZIMMERMANN, Sergio; NEW, Michael Bernard. Grow-out Systems - Polyculture and Integrated Culture. In: NEW, Michael B. Freshwater Prawn Culture: The Farming of Macrobrachium rosenbergii. London: Blackwell Science, 2000. cap. 11. 